\title{
HELIUM TRANSPORT AND EXHAUST STUDIES IN ENHANCED CONFINEMENT REGIMES IN DIII-D
}

by

M.R. WADE, D.L. HILLIS, J.T. HOGAN, M.A. MAHDAVI, R. MAINGI, W.P. WEST, K.H. BURRELL, D.F. FINKENTHAL, P. GOHIL, R.J. GROEBNER, R.-M. HONG, D.H. KELLMAN, M.M. MENON, J.C. PHILLIPS, R.P. SERAYDARIAN, and The DIII-D TEAM 
DISCLAIMER

This report was prepared as an account of work sponsored by an agency of the United States Government. Neither the United States Government nor any agency thereof, nor any of their employees, makes any warranty, express or implied, or assumes any legal liability or responsibility for the accuracy, completeness, or usefulness of any information, apparatus, produce, or process disclosed, or represents that its use would not infringe privately owned rights. Reference herein to any specific commercial product, process, or service by trade name, trademark, manufacturer, or otherwise, does not necessarily constitute or imply its endorsement, recommendation, or favoring by the United States Government or any agency thereof. The views and opinions of authors expressed herein do not necessarily state or reflect those of the United States Government or any agency thereof. 


\section{DISCLAIMER}

Portions of this document may be illegible in electronic image products. Images are produced from the best available original document. 


\section{CONF-941101--7 \\ GA-A21905}

\section{HELIUM TRANSPORT AND EXHAUST STUDIES IN ENHANCED CONFINEMENT REGIMES IN DIII-D}

by

M.R. WADE, ${ }^{*}$ D.L. HILLIS, ${ }^{*}$ J.T. HOGAN, ${ }^{*}$ M.A. MAHDAVI, R. MAINGI, $†$ W.P. WEST, K.H. BURRELL, D.F. FINKENTHAL, † P. GOHIL, R.J. GROEBNER, R.-M. HONG, D.H. KELLMAN, M.M. MENON, ${ }^{*}$ J.C. PHILLIPS, R.P. SERAYDARIAN, and The DIII-D TEAM

This is a preprint of an invited paper presented at the 36th Annual Meeting of the Division of Plasma Physics, November 7-11, 1994, in Minneapolis, Minnesota, and to be printed in the PHYSICS OF PLASMAS

Work supported by the U.S. Department of Energy under Contract Nos. DE-AC03-89ER51114, W-7405-ENG-48, DE-AC05-840R21400, and DE-AC04-94DP00789

*Oak RIdge National Laboratory.

toak Ridge Associated Universities.

FUniversity of California at Berkeley. 


\section{ABSTRACT}

A better understanding of helium transport in the plasma core and edge in enhanced confinement regimes is now emerging from recent experimental studies on DIII-D [Plasma Phys. and Contr. Fusion Research, 159 (1986)]. Overall, the results are encouraging. Significant helium exhaust $\left(\tau_{H e}^{*} / \tau_{E} \sim 11\right)$ has been obtained in a diverted, H-mode plasmas with edge-localized modes (ELMs) simultaneous with a central source of helium. There is no evidence of central peaking of the helium density profile even in the presence of this central source. Detailed analysis of the helium profile evolution indicates that the exhaust rate is limited by the exhaust efficiency of the pump $(\sim 5 \%)$ and not by the intrinsic helium transport properties of the plasma. Perturbative helium transport studies using gas puffing have shown that $D_{H e} / \chi_{\text {eff }} \sim 1$ in all confinement regimes studied to date (including $\mathrm{H}$-mode and VH-mode). Furthermore, there is no evidence of preferential accumulation of helium in any of these regimes. 


\section{CONTENTS}

ABSTRACT

I. INTRODUCTION

II. HELIUM EXHAUST STUDIES

III. HELIUM TRANSPORT STUDIES

IV. CONCLUSIONS

23

REFERENCES

25

ACKNOWLEDGMENTS

29 


\section{LIST OF FIGURES}

Fig. 1. Measured time evolution

Fig. 2. Time evolution of the helium density at $r=0.2$ as measured by charge-exchange recombination spectroscopy during the discharge described in Fig. 1

Fig. 3 Inverse gradient scale length of the helium density profile as inferred from CER measurements at times during the discharge described in Fig. 1

Fig. 4. Comparison of measured helium density and electron profiles

Fig. 5 Representative plot of the normalized flux $\Gamma \mathrm{He} / n_{\mathrm{He}}$ versus the helium density scale length $\nabla n \mathrm{He} / n_{\mathrm{He}}$ at a normalized radius of $\rho=0.3$

Fig. 6. Measured helium density evolution and the functional fit used to smooth the functional fit used to smooth the original data for six different CER channels during an ELMing $\mathrm{H}$-mode discharge

Fig. 7. Helium transport coefficients during a NBI power scan in ELMing $\mathrm{H}$-mode conditions

Fig. 8. Comparison of $D_{H e}$ and $\chi_{\text {eff }}$ 


\section{INTRODUCTION}

The viability and desirability of particular operating regimes in future, burning magnetic confinement devices are critically dependent on the ability to continuously and efficiently remove helium "ash" from the plasma core. In such devices, any enhancement in energy confinement properties of the plasma brings along with it substantial economic and engineering benefits. However, one must be careful to consider the entire picture and, in particular, the helium exhaust issue when assessing the desirability of various operating regimes. For example, one long-standing objection of enhanced confinement regimes has been the possibility that particle (and hence helium) removal would not be sufficient to prevent significant dilution of the deuterium-tritium fuel. Therefore, it is important that adequate helium $(\mathrm{He})$ exhaust in any operating regime be demonstrated before such a scenario can be considered as a viable option for a burning plasma device, such as the International Thermonuclear Experimental Reactor (ITER). ${ }^{1}$ In this regard, experiments have been conducted on DIII-D ${ }^{2}$ to study the helium transport and exhaust properties of presently obtained enhanced confinement regimes, namely $\mathrm{H}$ (high) mode and $\mathrm{VH}$ (very high) mode. The results of these studies indicate that core transport rates for helium will be sufficient (i.e., will not be the limiting factor) for adequate helium exhaust in future, burning plasma devices in either of these confinement regimes.

In assessing the helium exhaust capabilities of a given operating scenario, there are several physics issues that must be addressed. The helium exhaust problem is truly global in nature since the helium ash in a reactor will be deposited in the plasma core and can only be removed from the system via pumping at the plasma edge. In this regard, the figure of merit generally used in judging global helium exhaust characteristics is the ratio of the global residence time of the He ash within the plasma chamber $\tau_{H e}^{*}=\tau_{H e} / \varepsilon_{H e}$ to the plasma energy confinement time 
$\tau_{E}$. Here, $\tau_{H e}$ is the helium particle confinement time within the plasma core and $\varepsilon_{H e}$ is the exhaust efficiency of helium defined as $\varepsilon_{H e}=Q_{E x h} /\left(\Gamma_{H e} A_{p l}\right)$ where $Q_{E x h}$ is the exhaust rate for helium and $\Gamma_{H e} A_{p l}$ is the core helium efflux. Studies have shown that successful operation of a reactor can be maintained only if the He ash is removed from the system in less than 7-15 energy confinement times (i.e., $\tau_{H e}^{*} / \tau_{E} \leq 7-15$ ), depending on the impurity content of the plasma[3]. Previous studies on several tokamak devices have demonstrated that adequate $\mathrm{He}$ exhaust can be obtained during L- (low-) mode plasma operation ${ }^{4-7}$ and in somewhat enhanced confinement regimes such as the supershot regime ${ }^{8}$ or I-mode regime. ${ }^{9}$ However, in terms of energy confinement, heat removal, and particle handling characteristics, the most promising, steady-state operating regime obtained to date is $\mathrm{H}$-mode in a diverted, magnetic configuration. A long-standing objection to this regime has been the possibility that particle (and hence ash) removal would be insufficient. In this regard, recent helium exhaust experiments have been conducted on DIII-D using a divertor cryopump ${ }^{10-12}$ in which $\tau_{H e}^{*} / \tau_{E}$ $\sim 8$ has been achieved simultaneously with good energy confinement in an $\mathrm{H}$-mode plasma with edge localized modes (ELMs). ${ }^{13}$. These results have been extended in the present work to include helium exhaust with a centrally deposited source of helium (using helium neutral beam injection). Such a demonstration is as close to a full simulation of the situation in ITER that can be obtained on present-day devices.

Unfortunately, using $\tau_{\mathrm{He}}^{*}$ as a figure of merit in present-day devices can be misleading because $\tau_{H e}^{*}$ in a particular device is strongly dependent on machine configuration such that the same value of $\tau_{H e}^{*}$ can conceivably be obtained in widely different scenarios, some of which are not viable candidates for ITER. Hence, demonstration that this condition can be met in DIII-D and other present-day devices is necessary but not sufficient evidence that adequate helium exhaust can be expected in a similar operating scenario in ITER. Therefore, the basic physics controlling the flow of helium from the plasma core to the pumping plenum also must be fully 
characterized since physics understanding obtained in these areas can be extrapolated from present-day devices to ITER. In this regard, several issues are important including local relationships of helium transport, electron and main particle transport, and energy transport in the plasma core, as well as edge helium transport and the pumping efficiency of the system. Of particular importance in the area of core transport is the relationship of core energy transport and thermal helium transport. This results from the fact that in a reactor the primary source of both thermal helium and energy will be from the slowing down of fusion-produced alpha particles. In this case, the continuity equations for helium and energy are coupled, and the ratio of the helium diffisivity $D_{H e}$ to the thermal diffisivity $\chi_{\text {eff }}$ plays an important role in determining the helium density profile in the plasma core. ${ }^{8}$ For example, simulations of helium exhaust in ITER have shown that when the ratio of $D_{\mathrm{He}} / \chi_{\text {eff }}$ is decreased from 2.0 to 0.5 , the helium content of the plasma increases by $75 \%$ and the fusion power. ${ }^{14}$ decreases by $20 \%$. An even stronger dependence is expected for values of $D_{H e} / \chi_{\text {eff }}<0.5$. This particular aspect of helium transport dynamics in a reactor is of particular importance when comparing the advantages and disadvantages of various confinement regimes. For example, significant increases in energy confinment allowing better reactor performance may be offset completely by even larger increases in helium confinement. Previous transport studies on the Tokamak Fusion Test Reactor (TFTR) have shown that $D_{H e} / \chi_{\text {eff }} \sim 1$ in both L-mode and supershot regimes, ${ }^{8}$ suggesting that $D / \chi$ is not highly sensitive to changes in operating regimes. To extend these results to other enhanced confinement regimes, studies characterizing helium transport in $\mathrm{H}$-mode and VH-mode conditions have been carried out on DIII-D.

The results of experiments examining $\mathrm{He}$ exhaust in an $\mathrm{H}$-mode, diverted plasma in the presence of a central He source are described in Section II. These experiments have successfully demonstrated the capability to exhaust helium from an ELMing $\mathrm{H}$-mode discharge, with $\tau_{H e}^{*} / \tau_{H e} \sim 11$. Section III contains a description of experiments performed to 
assess helium transport in various confinement regimes in DIII-D. Particular emphasis is place on comparing the helium density profile shape to the electron density profile shape to assess preferential accumulation of helium and comparisons of $D_{H e} / \chi_{\text {eff }}$ in various operating regimes. Conclusions drawn from these results are outlined in Section IV. 


\section{HELIUM EXHAUST STUDIES}

These experiments were made possible by a recent upgrade of the DIII-D neutral beam system to include the capability of 2.0-s steady-state He neutral beam injection (NBI). With this upgrade, delivered powers on the order of $1.5 \mathrm{MW}$ per source (at $75 \mathrm{keV}$ injection energy) are routinely available for up to $2.0-\mathrm{s}$ pulses. Helium exhaust in these experiments is accomplished by condensing an argon (Ar) frost layer on the liquid helium surface of the DIII-D divertor cryopump between successive plasma discharges by isolating the vacuum chamber from the external turbomolecular pumps and injecting a known amount of $\mathrm{Ar}$ into the main vacuum chamber. In this manner, a layer of $\sim 3000$ Torr-liters $(\sim 3.0 \mu \mathrm{m}$ thick layer) is condensed on the pump, providing a measured pumping speed for $\mathrm{He}$ of approximately $18,000 \mathrm{l} / \mathrm{s}$ when the layer is fresh. It should be pointed out that off-line tests have shown that the pumping speed of this Ar frost is severely degraded as the total amount of deuterium condensed on the Ar frost increases.

In a situation with a simultaneous source and sink of helium, the global He particle balance equation takes the form:

$$
d N_{H e} / d t=S_{H e}-Q_{H e}
$$

where $N_{H e}$ is the total number of $\mathrm{He}$ ions in the plasma, $S_{\mathrm{He}}$ and $Q_{\mathrm{He}}$ are the instantaneous $\mathrm{He}$ source and exhaust rates, respectively. Since the He exhaust rate can be written as the product of the exhaust efficiency $\varepsilon_{H e}$, defined above, and the core helium efflux $N_{H e} / \tau_{H e}$, then this equation takes on the more familiar form:

$$
d N_{H e} / d t=S_{H e}-N_{H e} / \tau_{H e}^{*}
$$


where $\tau_{H e}^{*}=\tau_{H e} / \varepsilon_{H e}$. The general solution to this equation for a source turning on at time $t_{o}$ is:

$$
N_{H e}(t)=N_{H e}\left(t_{o}\right)+\left[S_{H e} \tau_{H e}^{*}-N_{H e}\left(t_{o}\right)\right]\left\{1-\exp \left[-\frac{\left(t-t_{o}\right)}{\tau_{H e}^{*}}\right]\right\}
$$

provided $S_{H e}$ and $\tau_{H e}^{*}$ are constant for $t>t_{o}$. In the limit that $\tau_{H e}^{*}$ approaches $\infty$ (i.e., no helium exhaust), Eq. (2) reduces to $N_{H e}(t)=N_{H e}\left(t_{o}\right)+S_{H e}\left(t-t_{o}\right)$.

The temporal evolution of a typical He exhaust discharge in DIII-D with He NBI is shown in Fig. 1. For the experiments discussed here, a lower, single-null, divertor configuration was used with a plasma current of 1.0 MA and a major radius of $\sim 1.67 \mathrm{~m}$. Control of the outer-strike point (OSP) is essential in these experiments not only to maximize helium exhaust during the He NBI phase of the discharge but also to minimize the contamination of the Ar frost prior to the initiation of He NBI. To accomplish this, the OSP is maintained approximately $15 \mathrm{~cm}$ from the baffle entrance throughout the initiation and early phases of the discharge. With the OSP in this location, the interaction between the divertor plasma and pumping plenum is minimized and the obtained exhaust rates are generally small. Just before initiation of $\mathrm{He}$ NBI, the OSP is rapidly swept to within $1 \mathrm{~cm}$ of the baffle entrance to initiate maximum exhaust. The OSP is then maintained in this location throughout the He NBI/exhaust phase of the discharge. Helium NBI is applied starting at $2.0 \mathrm{~s}$ and maintained for $1.4 \mathrm{~s}$, providing a $\mathrm{He}$ particle input rate of approximately 7 Torr- $1 / \mathrm{s}\left(\sim 2.5 \times 10^{20}\right.$ particles $\left./ \mathrm{s}\right)$.

As is evident from Fig. 1(a-b), the background plasma conditions are maintained nearly constant throughout the He NBI/exhaust phase of the discharge with the line-averaged plasma density being approximately $3.5 \times 10^{19} \mathrm{~m}^{-3}$ and the central electron temperature approximately $3.0 \mathrm{keV}$. Constant plasma density is maintained through feedback control of the deuterium gas 

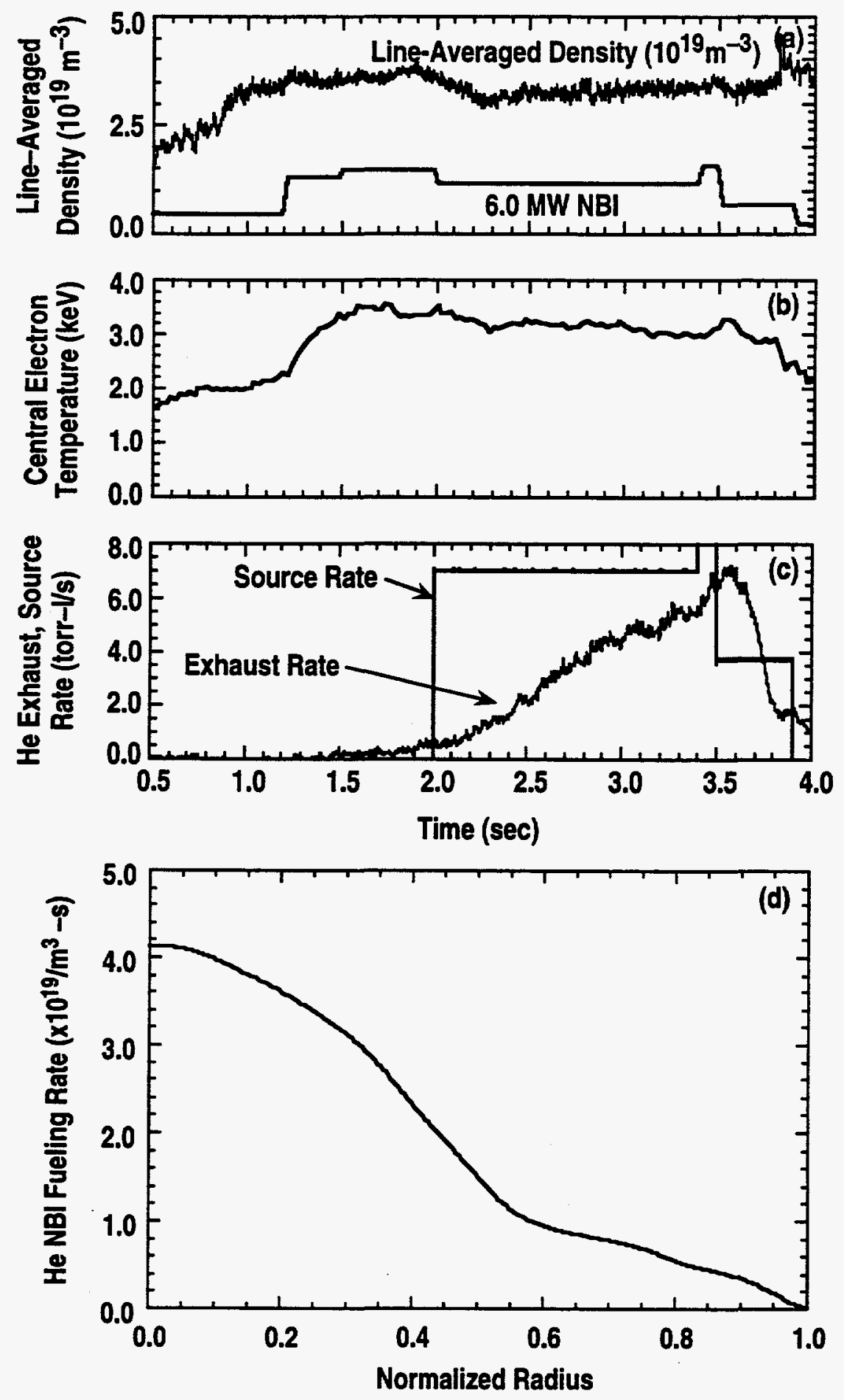

Fig. 1. Measured time evolution of the (a) plasma density and total injected power $\left(D^{\circ}+\right.$ $\left.\mathrm{He}^{\mathrm{O}}\right)$, (b) central electron temperature, and (c) helium source and exhaust rates along with (d) the computed He deposition profile at $t=3.0 \mathrm{~s}$ during an ELMing $\mathrm{H}$-mode discharge with simultaneous helium $\mathrm{NBI}$ and helium exhaust. 
fueling rate with the line-averaged plasma density. As expected for these plasma conditions, calculations give a peaked particle deposition profile [shown in Fig. 1(a)]. A significant amount of this centrally deposited helium is exhausted during the exhaust phase as is evidenced by Fig. 1(c). The He exhaust rate is estimated as the product of the measured helium partial pressure in the divertor via a modified penning gauge 15 and an approximated He pumping speed of $14,000 \mathrm{l} / \mathrm{s}$. This estimate of the pumping speed is less than the nominal $18,000 \mathrm{l} / \mathrm{s}$ measured when the Ar frost layer is fresh because of contamination of the Ar frost layer by deuterium.

The temporal evolution of the He density near the plasma center (normalized minor radius $\rho=0.2$ ) during the He NBL/exhaust phase of this discharge is shown in Fig. 2. This measurement is provided by a high resolution spectroscopy system using the techniques of active charge-exchange recombination (CER) spectroscopy. The DIII-D CER system has 32 channels that span the entire cross section with excellent spatial resolution over the entire profile ( $3 \mathrm{~cm}$ in the core, $3 \mathrm{~mm}$ at the edge). ${ }^{16}$ The He density profile is inferred from measurements of the intensities of the He II $n=4-3$ transition at $4685.68 \AA$ induced by charge-exchange excitation with energetic deuterium neutrals from neutral beam injection (NBI). The evolution of the measured He density in the core shown in Fig. 2 is seen to be similar to the expected time behavior of the total inventory of He in the plasma described by Eq. (2). The long e-folding rise time of the helium density is expected since the helium exhaust rate is not sufficient to match the helium source rate throughout this phase of the discharge [see Fig. 1(d)]. The measured helium concentration (relative to the electron density $n_{e}$ ) at $3.4 \mathrm{~s}$ is approximately $20 \%$. Also shown in Fig. 2 is the predicted evolution of the helium density at this radius in a case with no helium exhaust (i.e., $\tau_{H e}^{*}=\infty$ ). From this comparison, it is obvious that a substantial amount of $\mathrm{He}$ is exhausted from the system throughout the exhaust phase. 


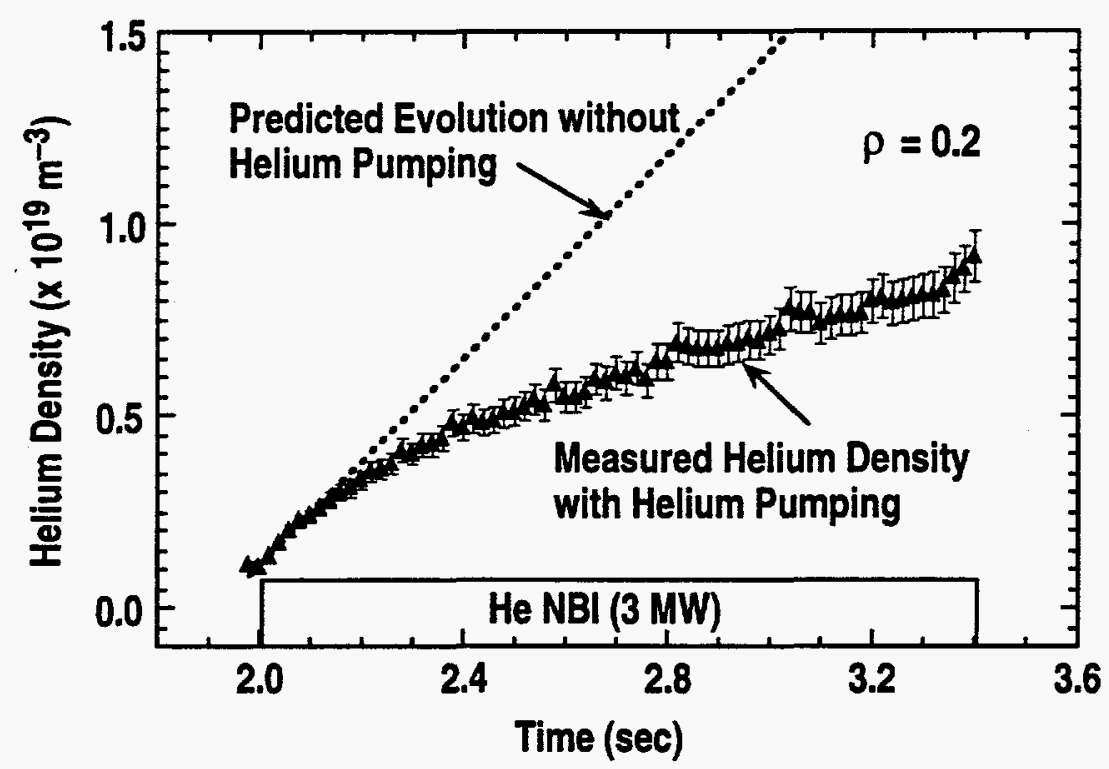

Fig. 2. Time evolution of the helium density at $\rho=0.2$ as measured by charge-exchange recombination spectroscopy during the discharge described in Fig. 1. The dashed line is the predicted evolution of the helium density in a case without helium pumping.

From CER measurements of the helium density profile evolution during He NBI, the time dependence of the total plasma inventory of $\mathrm{He}$ ions can be determined directly. The characteristic helium residence time in the system $\tau_{H e}^{*}$ can then be determined by the best fit to Eq. (2). Such analysis provides a value of $\tau_{H e}^{*}=1.45 \mathrm{~s}$. From measurements of the magnetic and kinetic stored energy, the energy confinement time in this particular discharge is $\tau_{E} \approx 0.135 \mathrm{~s}$, which is slightly higher than what would be predicted from DIII-D/JET ELM-free H-mode scaling. 15 Combining this information, $\tau_{H e}^{*} / \tau_{E}$ is approximately 11 - clearly within the range generally considered necessary for successful operation of future fusion reactors, such as ITER.

The He density profile shape as measured by CER remains essentially the same throughout the He NBI/exhaust phase of this discharge. To elucidate the details of the profile, the evolution of the inverse gradient scale length is shown in Fig 3. This figure clearly shows that the profile peaks strongly shortly after the initiation of $\mathrm{He} \mathrm{NBI}$, but then relaxes to the pre-He 


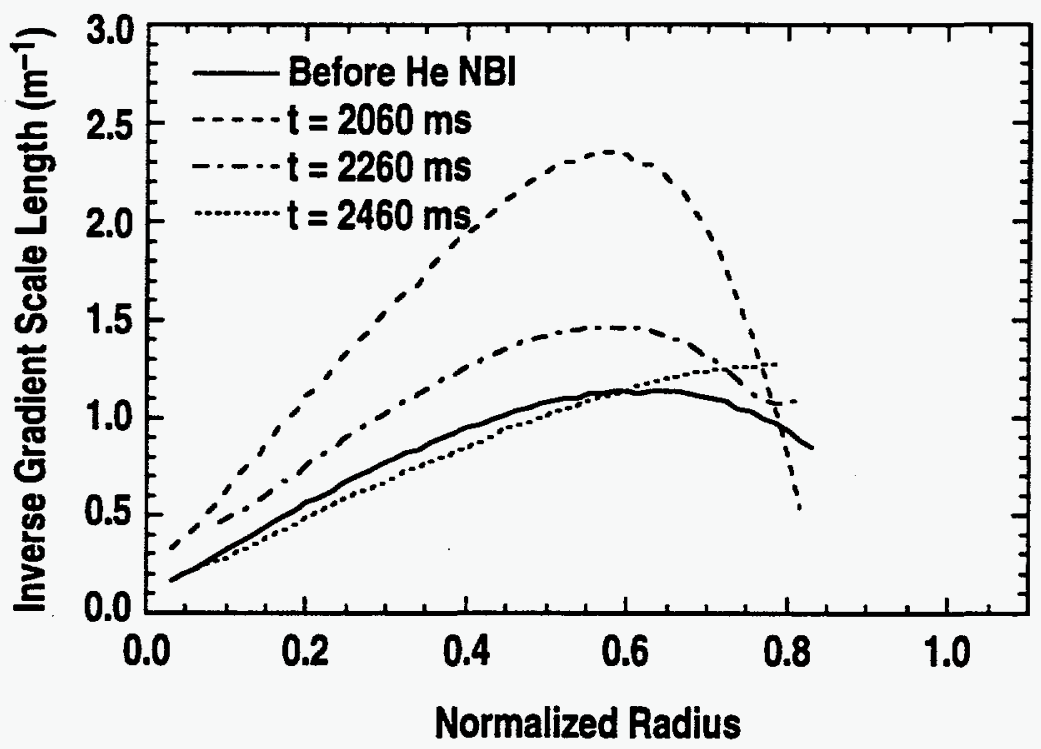

Fig. 3. Inverse gradient scale length of the helium density profile $\left(1 / n_{\mathrm{He}} d n_{\mathrm{He}} / \mathrm{dp}\right)$ as inferred from CER measurements at times during the discharge described in Fig. 1. Helium NBI is applied from $2.0 \mathrm{~s}$ to $3.4 \mathrm{~s}$.

NBI profile within approximately $300 \mathrm{~ms}$ of the onset of He NBI. This relaxation is most likely due to the He source changing from being predominantly in the plasma core (from He NBI) early in the He NBI phase to predominantly at the edge (from recycled $\mathrm{He}$ ) late in the $\mathrm{He}$ NBI/exhaust phase. These observations coupled with the fact that the profiles are fairly flat even in the presence of a central He source indicate substantial transport rates within the plasma core. This suggests that the exhaust of $\mathrm{He}$ is limited by the effective exhaust efficiency of the pumping configuration and not by transport of $\mathrm{He}$ within the plasma core. This also implies that the He particle confinement time in the core $\tau_{H e}$ is much less than the residence time of He within the system $\tau_{H e}^{*}$. 


\section{HELIUM TRANSPORT STUDIES}

As was pointed out in the previous section, core transport rates do not appear to be the limiting factor in the attainable helium exhaust rates on DIII-D. To verify these qualitative observations, we have also conducted helium transport studies in order to make a more quantitative assessment of core transport rates in DIII-D. A by-product of these studies is the development of a helium transport database that should provide much needed information in the design of ITER and future burning devices.

To permit accurate determination of local He transport properties, He transport studies in DIII-D are conducted by injecting a short $(<50 \mathrm{~ms})$ puff of He gas during an otherwise steadystate phase of the discharge. Because of the continuous evolution of the background plasma in ELM-free $\mathrm{H}$-mode and VH-mode discharges, gas injection into the steady-state phase is clearly not possible and makes transport analysis of these discharges more difficult. Sufficient He is introduced to bring the He concentration to $-3 \%-10 \%$ of $n_{e}$. The He density profile evolution subsequent to this puff is inferred from measurements of the intensities of the He II $n=4-3$ transition at $4685.68 \AA$. Modulation of the neutral beams at a frequency of $100 \mathrm{~Hz}$ was used to simplify computational analysis of the measured CER spectra. When using beam modulation, the minimum temporal resolution for reconstructing He density profiles is $10 \mathrm{~ms}$. For most of the experimental results discussed below, a lower single-null divertor configuration was used with a toroidal magnetic field of $2.1 \mathrm{~T}$ and a major radius of $1.67 \mathrm{~m}$. The one exception is the VH-mode results which were obtained in a double-null divertor configuration. The vacuum vessel walls were conditioned via boronization (conducted several operating days before these experiments) and via helium glow discharge cleaning (He GDC) between shots. 
One of the primary obstacles that must be addressed in determining the transport coefficients from these measurements is the systematic uncertainties associated with the measurement itself. In particular, reducing the systematic uncertainties that affect the helium profile shape is critical. These uncertainties arise from systematic errors in the channel-tochannel calibration of the system, beam stopping cross sections, and plume effects. To reduce the uncertainties in the channel-to-channel calibration, the system is calibrated using a technique in which the neutral beams are injected into a vacuum vessel that has been backfilled to a fairly high pressure ( $0.5 \mathrm{mTorr})$ with helium gas. The flourescence caused by the beam passing through the helium gas is observed via the CER system providing an accurate chord-tochord calibration. 17 Note that uncertainties in the absolute helium density are generally much larger $(\sim 5-10 \%)$ than the uncertainties in the profile shape because of systematic uncertainties in the calibration process, charge-exchange excitation rates, and beam properties.

The most universal and possibly the most striking result found to date during these experiments is that the helium density profile measured by CER and the electron density profile measured by Thomson scattering[18] have nearly the same shape in all types of discharges studied to date (L-mode, ELM-free H-mode, ELMing H-mode, and VH-mode). A comparison of the electron density and helium density profiles measured in each of these confinement regimes is shown in Fig. 4. The profiles in each case were taken approximately $1.0 \mathrm{~s}$ after the He gas puff (at the termination of the VH-mode phase in the VH-mode case), allowing the He enough time to come into equilibrium subsequent to the puff. Although certain details of the profile shapes are not exactly the same, there is clearly no evidence of preferential accumulation of helium in any of these discharges. These observations suggest that there is a strong link between deuterium and helium transport and that preferential accumulation of $\mathrm{He}$ in the core of ITER should not be a problem in either $\mathrm{L}$-mode or $\mathrm{H}$-mode operation. The large error bars in the ELMing 

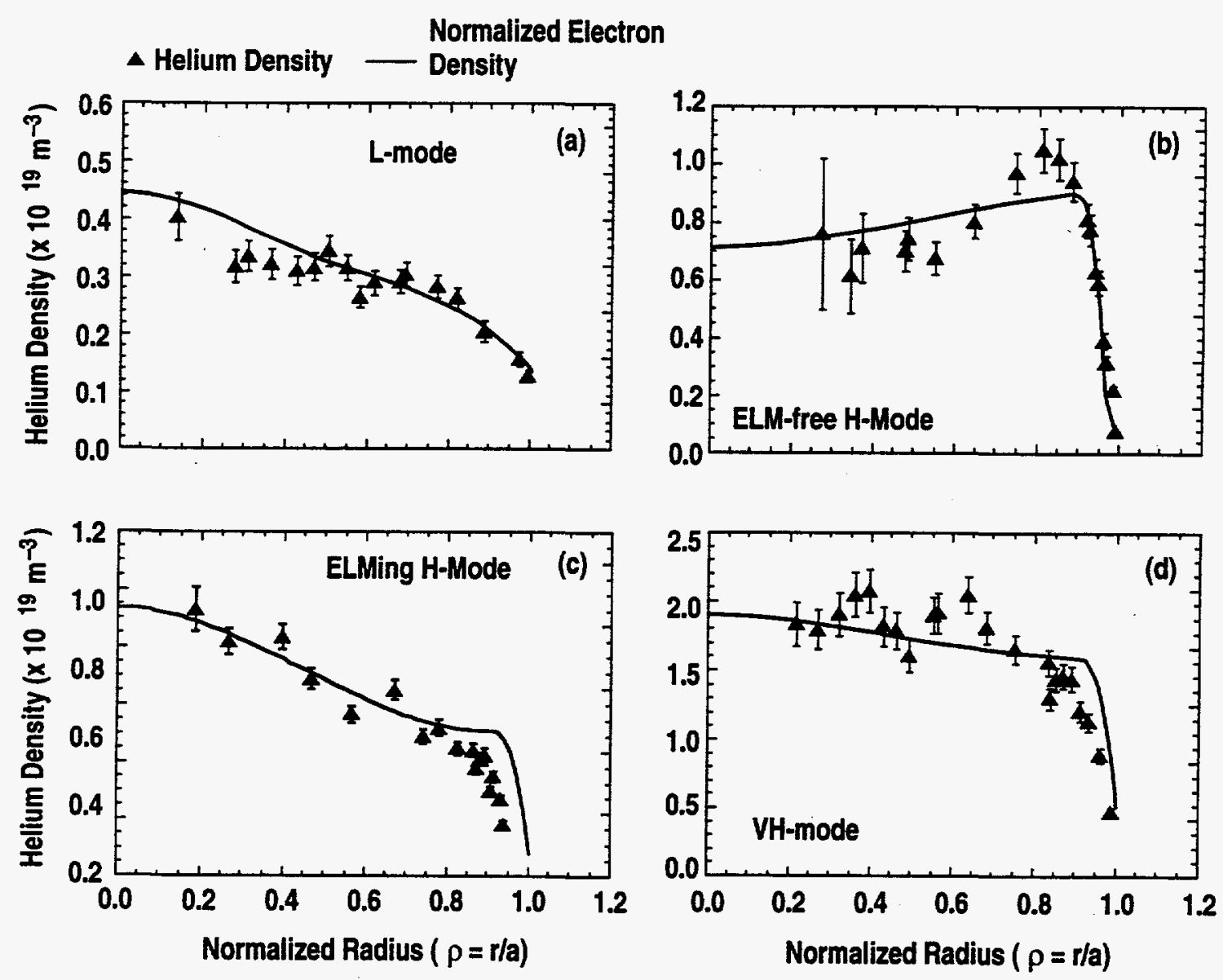

Fig. 4. Comparison of measured helium density and electron profiles in (a) L-mode, (b) ELM-free $\mathrm{H}$-mode, (c) ELMing $\mathrm{H}$-mode, and (d) $\mathrm{VH}$-mode discharges. The solid curve is a spline fit to the measured electron density profile that has been renormalized for comparison purposes.

$\mathrm{H}$-mode case as compared to the other cases are due to the higher plasma density and the resulting larger uncertainties in the beam attenuation calculation. These error bars include all systematic and statistical errors associated with the calculation of the absolute density of helium. As described earlier, the uncertainties in the density profile shape are considerably smaller than those shown here.

Although the data in Fig. 4 suggests a strong link between deuterium and helium transport, it should be pointed out that this data provides no concrete information on the absolute 
magnitudes of the transport coefficients for deuterium and helium. To obtain this information, perturbative helium transport studies are required. These transport coefficients are determined by first determining the helium particle flux $\Gamma_{H e}$ from the measured evolution of the He density profile by evaluating the continuity equation,

$$
\frac{\partial n_{H e}}{\partial t}=-\nabla \cdot \Gamma_{H e}+S_{H e}
$$

where $n_{\mathrm{He}}$ is the helium density and $S_{\mathrm{He}}$ is the helium source rate. The helium particle flux is assumed to be made up of diffusive and convective flows, represented in the form:

$$
\Gamma_{H e}(r, t)=-D_{H e}(r) \nabla n_{H e}(r, t)+n_{H e}(r, t) V_{H e}(r)
$$

where $D_{H e}$ is the anomalous diffusion coefficient and $V_{H e}$ is the convective velocity. Note that $D_{H e}$ and $V_{H e}$ are assumed to be time-independent. From CER measurements, the time evolution of the He density subsequent to a perturbation such as a gas puff can be reconstructed in detail. From such data, the helium flux $\Gamma_{H e}$ can then be inferred directly through the inversion of Eq. (3) assuming $S_{H e}=0$ subsequent to the He gas puff. Note that such analysis is only accurate inward of the region of He ionization at the plasma edge. The helium flux could conceivably be calculated in this ionization region, but in practice is quite difficult.

Examination of Eq. (4) suggests that there is an offset linear relationship between the normalized flux $\Gamma_{\mathrm{He}} / n_{\mathrm{He}}$ and the density scale length $\nabla n_{\mathrm{He}} / n_{\mathrm{He}}$. A representative plot of $\Gamma_{\mathrm{He}} / n_{\mathrm{He}}$ as a function of $\nabla n_{\mathrm{He}} / n_{\mathrm{He}}$ from analysis done for DIII-D data at a particular radial location are shown in Fig. 5. From such a curve, the diffusion coefficient $D_{\mathrm{He}}$ is then simply the absolute value of the slope of the best-fitting line to this data and the convective velocity $V_{H e}$ is the intercept [see Eq. (4)]. Note that each point on this plot is for a different time during the helium profile evolution. Similar analysis of this type has been done in main particle and 


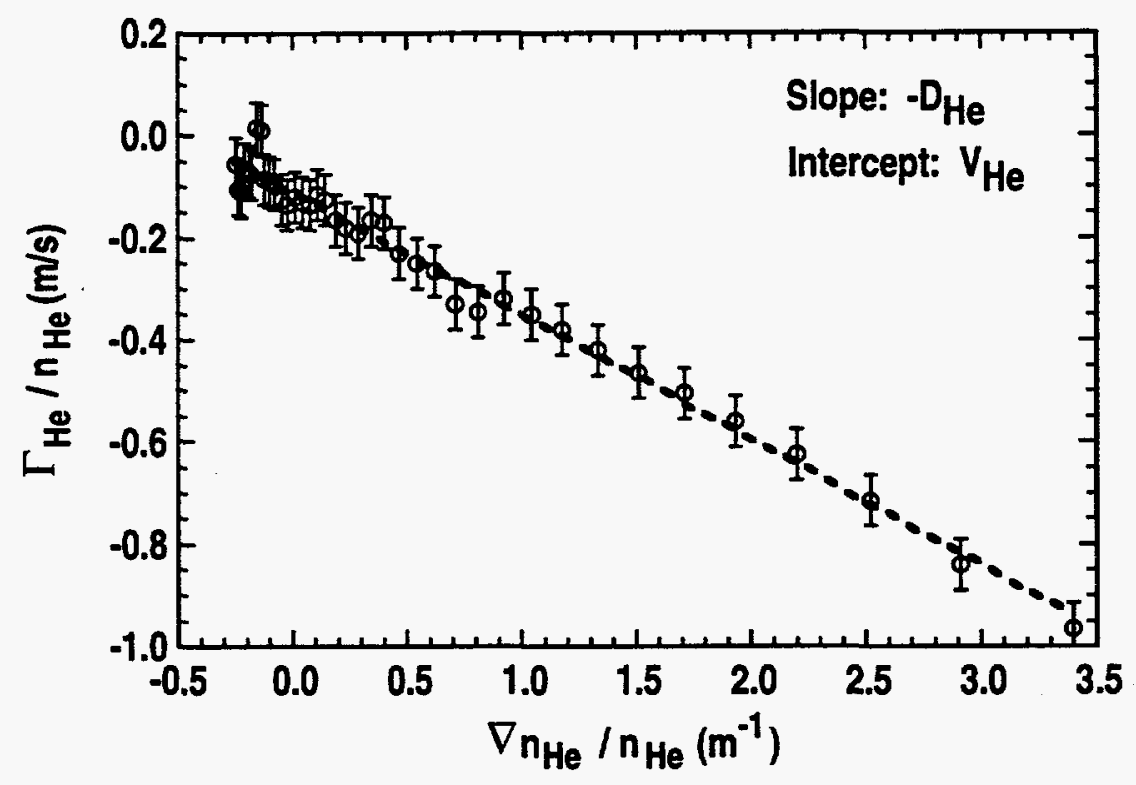

Fig. 5. Representative plot of the normalized flux $\Gamma_{H e} / n_{H e}$ versus the helium density scale length $\nabla n_{\mathrm{He}} / n_{\mathrm{He}}$ at a normlized radius of $\rho=0.3$.

helium transport studies on TFTR $^{8,19}$ and main particle transport studies using pellet injection on the Joint European Torus (JET). ${ }^{20}$ Assuming that the helium is introduced at the trace level, the linear behavior observed in Fig. 5 is consistent with time-independent transport coefficients.

The data for Fig. 5 is generated by first "smoothing" the measured time evolution of each channel individually by performing a least-squares fit to a carefully chosen functional form that reproduces the temporal trends of the data quite accurately. An example of this process is shown in Fig. 6 where the measured data for six different CER channels are compared with the function chosen to represent the data. In general, two different fitting functions are used. For normalized radii $\rho<0.5$, the function $A_{1}+A_{2} \tanh \left[A_{3}\left(t-t_{o}-A_{4}\right)\right]$ is used while for normalized radii $\rho>0.5$, the function $A_{1}+A_{2} \exp \left[-A_{3}\left(t-t_{o}\right)\right]+A_{4} \exp \left[-A_{5}\left(t-t_{o}\right)\right]$ where $t_{o}$ is the time of the He gas puff. As is evident in Fig. 6, these functions reproduce the temporal trends of the data quite accurately. Because there are generally many more data points than free 

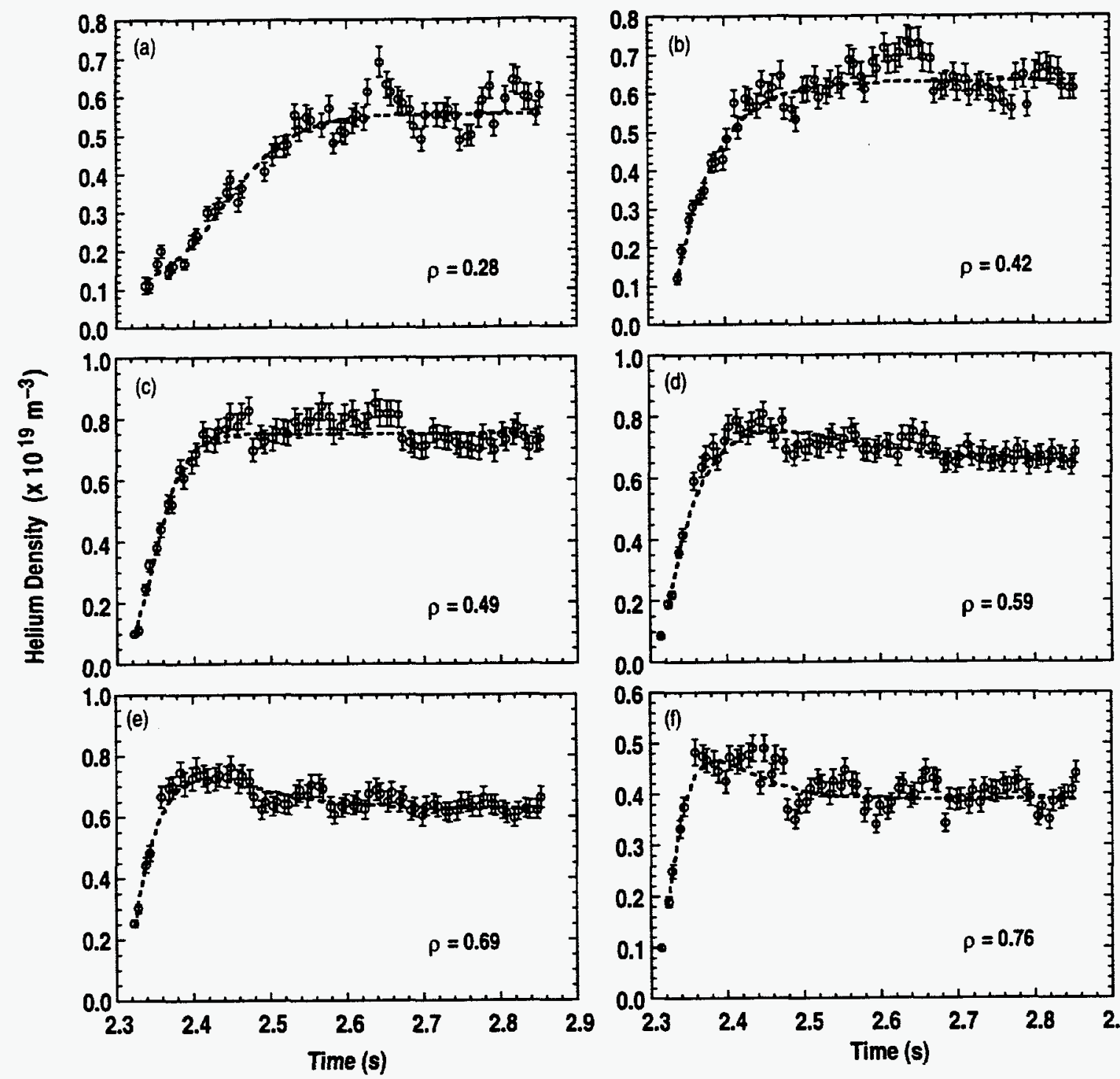

Fig. 6. Measured helium density evolution (circles) and the functional fit used to smooth the orignal data (dashed lines) for six different CER channels during an ELMing $\mathrm{H}$-mode discharge. The function fit used for (a)-(c) has the form $A_{1}+A_{2} \tanh \left[A_{3}\left(t-t_{o}-A_{4}\right)\right]$ while the fit for (d)-(f) has the form $A_{1}+A_{2} \exp \left[-A_{3}\left(t-t_{o}\right)\right]+A_{4} \exp \left[-A_{5}\left(t-t_{o}\right)\right]$.

parameters in this fitting process, the uncertainties associated with the fit are generally much smaller than the uncertainties in the measured data. Therefore, to properly estimate the uncertainties for subsequent analysis, the error bars from the measured data are used instead of the error bars of the functional fit. The helium density profile at each time step is then determined via least-squares profile fitting. Finally, the helium flux is computed through 
inversion of Eq. (3). In principle, one could generate Fig. 5 by first determining the the helium density profile at each time step via least-squares profile fitting and then computing the helium flux through inversion of Eq. (3). Unfortunately, this process generally leads to a helium density profile that is smooth in space but not in time - thereby making computation of the helium flux problematic. This effect mainly results from the sensitivity of the least-squares fitting technique to the statistical "noise" in the time history of the measured data. The approach outlined above has been found to produce a density profile evolution that is smooth in both time and space, making the data in Fig. 5 less "noisy". Such an approach is consistent with the basic assumption that the He transport coefficents are constant over the time period of interest resulting in a smooth evolution of the helium density at each radial location. The main drawback of this technique is that possible rapid transport due to non-steady-state effects (such as sawteeth and ELMs) are not properly taken into account, and the deduced transport coefficents are effectively a time average of the $\mathrm{dc}$ component of $\mathrm{He}$ transport on the background plasma and the transport of He due to these time-localized effects.

In past helium transport studies on DIII-D, the determination of He transport coefficients has been done via predictive modeling using the MIST code. 21 Such modeling is generally difficult and sometimes uncertain in the case of a highly recycling gas such as helium because of the difficulty in treating the plasma edge properly. The choice of the local analysis described above obviates these difficulties and makes the analysis more deterministic and less predictive in nature. To test the accuracy of such an approach, MIST simulations of several He transport shots have been performed using the transport coefficients derived from this local analysis. To remove the effect of the edge model in these simulations, a time-dependent boundary condition was imposed on the helium density at a plasma normalized radius near $\rho=0.7$. The time evolution of this boundary condition was chosen to match the time evolution of the helium density as measured by the nearest CER chord to this radial location. Note that in this case the MIST simulation does not suffer from the aforementioned uncertainties at the plasma edge 
because of the imposed boundary condition. The comparison of the simulation with the data is excellent in most cases, though in some cases there is difficulty in matching both the short-term $(<100 \mathrm{~ms}$ after the puff) and the long-term behavior of the measured evolution with a single set of transport coefficients. This effect seems to occur in discharges in which the helium gas puff is quite large, on the order of $10 \%$ of the plasma density. In this case, it is possible that the size of the gas puff perturbs the background plasma (and therefore the transport properties) temporarily. Other mechanisms for these differences are presently under investigation.

In order that a comparison could be made between helium diffusivity and thermal diffusivity, a local power balance analysis was also performed for these discharges. Because the ion and electron heat channels are closely coupled (i.e., $T_{e} \approx T_{i}$ ) in these discharges, it is difficult to separately determine $\chi_{e}$ and $\chi_{i}$ because of uncertainties in the electron-ion heat transfer term. Therefore, we have chosen to parameterize the heat diffusivity in terms of a single-fluid heat diffusivity $\chi_{\text {eff }}$ defined as:

$$
\chi_{e f f}=-\frac{Q_{e}+Q_{i}}{n_{e} \nabla T_{e}+n_{i} \nabla T_{i}}
$$

where $Q_{e}$ and $Q_{i}$ are the electron and ion heat fluxes, respectively. These heat fluxes are computed using the ONETWO transport code 22 which takes as input experimentally measured profiles of $n_{e}, T_{e}, T_{i}$, and $Z_{\text {eff }}$. The uncertainty in the inferred value of $\chi_{\text {eff }}$ is determined by systematically varying the input data within their ranges of uncertainty and combining the errors with the assumption that the inputs are uncorrelated.

As an example of the information available from the analysis approach described above, Fig. 7 shows the variation of $D_{H e}$ and $V_{H e}$ during an NBI power scan at a plasma current $I_{p}$ of 1.0 MA. All of these discharges are ELMing $\mathrm{H}$-mode discharges. From this figure, it is apparent that $D_{H e}$ increases in magnitude with increasing NB power while the magnitude of 

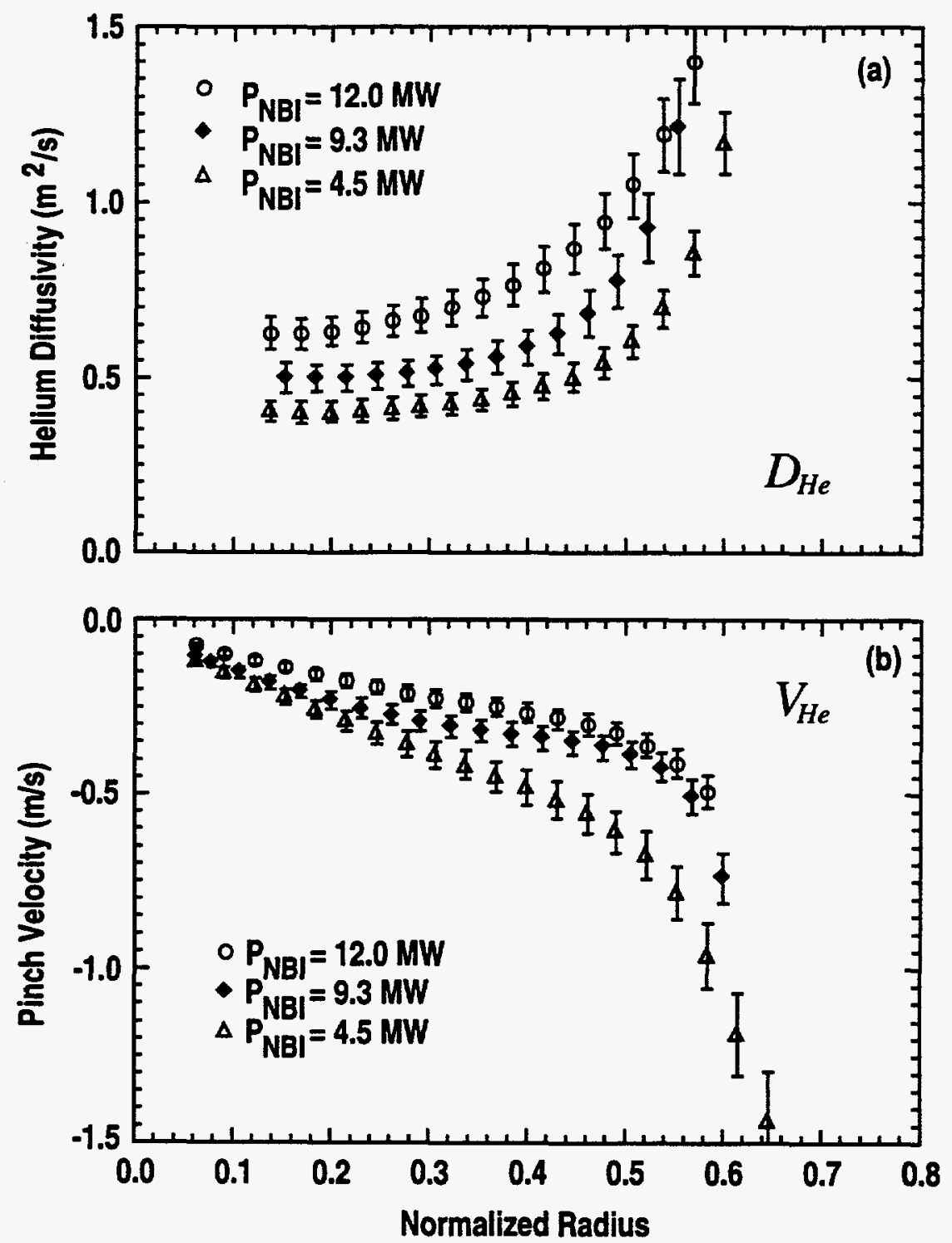

Fig. 7. Helium transport coefficients during a NBI power scan in ELMing $\mathrm{H}$-mode conditons (a) The helium diffisuvity $D_{H e}$ and (b) the pinch velocity $V_{H e}$. Note that negative values of $V_{H e}$ indicate inward convection.

$V_{H e}$ decreases. This degradation in confinement is qualitatively consistent with the results from global energy confinement scaling studies that show that $\tau_{E}$ decreases with increasing auxiliary power. 23 However, both of these trends are favorable in terms of extrapolation to future, high-power machines since a larger $D_{H e}$ implies faster helium transport from the plasma 
center to edge and smaller $V_{H e}$ implies less peaking of the helium density profile. All of the $D_{\text {He }}$ profiles in Fig. 7 also indicate a strong increase in the transport rates for $\rho>0.5$. Similar increases are also seen in the inferred thermal diffusivity profiles. The error bars shown in Fig. 7 include both statistical and systematic uncertainties in the calculation of the helium flux and gradient.

As stated in the introduction, the relationship between energy transport and helium transport is important in determining the feasibility of a particular operating regime. To examine the tradeoff between energy transport and helium transport as energy confinement improves, experiments have been performed on DIII-D to compare $D_{H e} / \chi_{e f f}$ in L-mode, ELM-free H-mode, ELMing H-mode, and VH-mode discharges. The inferred radial profiles of $D_{H e}$ and $\chi_{\text {eff }}$ for each of these confinement regimes are shown in Fig. 8. In all cases, $D_{H e} / \chi_{\text {eff }} \sim 1$ over much of the plasma radius with $D_{H e} / \chi_{\text {eff }}$ being the smallest $(\approx 0.5)$ in the VH-mode case. These observations are consistent with previous measurements on TFTR that indicate $D_{H e} / \chi_{e f f} \sim 1$ in both L-mode and supershot regimes. ${ }^{8}$ Furthermore, both $D_{H e}$ and $\chi_{\text {eff }}$ have similar radial dependencies in each case though in the $\mathrm{H}$-mode cases, the $D_{H e}$ profile appears to be flatter than the $\chi_{\text {eff }}$ profile outside of $\rho=0.5$. The fact that $D_{H e} / \chi_{\text {eff }} \sim 1$ in all cases is a favorable result as far as helium accumulation is concerned in ITER though the trend to smaller values of $D_{H e} / \chi_{\text {eff }}$ as energy confinement improves may be cause for concern. Furthermore, the similarity in magnitude and in profile shape of $D_{H e}$ and $\chi_{\text {eff }}$ in all of these cases suggests that a strong link exists between thermal and particle transport in these discharges. 

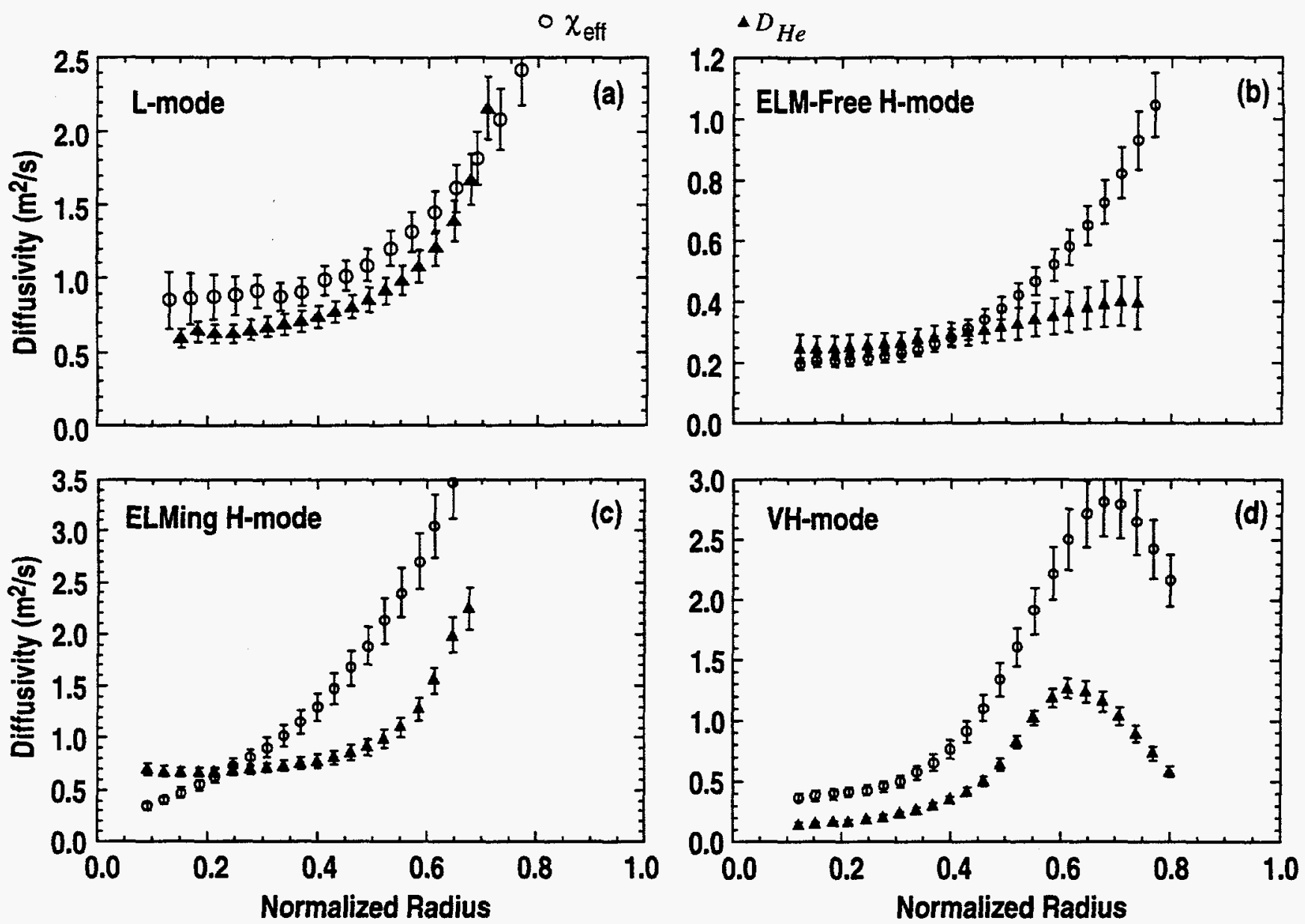

Fig. 8. Comparision of $D_{H e}$ and $\chi_{\text {eff }}$ in (a) L-mode, (b) ELM-free H-mode, (c) ELMing $\mathrm{H}$-mode, and (d) $\mathrm{VH}$-mode discharges. 


\section{CONCLUSIONS}

Although the data presented above is encouraging, one has to be careful in concluding from these data that helium removal will not be a problem in ITER. First and foremost, the helium exhaust in any machine is critically dependent on details of that device (e.g., core transport, geometric considerations, flux amplification, pumping efficiency, etc.) Hence, demonstration of adequate helium exhaust on DIII-D does not necessarily imply the same for ITER. Fortunately, the helium problem can be divided into two rather distinct areas: core transport and edge transport. In terms of the transport of He within the plasma core, the observations presented in Section II and III indicate that core transport rates for He will be sufficient for ITER in either ELMing $\mathrm{H}$-mode or L-mode conditions. In particular, the successful demonstration of helium exhaust with a central source of $\mathrm{He}$ in an ELMing $\mathrm{H}$-mode plasma is very encouraging, especially considering that the estimated exhaust efficiency in this experiment was only $\sim 5 \%$. Further optimization of these results should be possible, considering the small number of discharges in which helium exhaust has been performed thus far on DIII-D. An equally encouraging result for ITER is that there appears to be no preferential accumulation of He in any of the operating regimes studied to date. Furthermore, most of the results of Section III suggests that there is a universal correlation between helium transport and energy transport. This correlation provides hope that the benefits of future advances in energy confinement ( $\mathrm{VH}-$ mode and beyond) may be not be offset by simultaneous, undesirable increases in $\mathrm{He}$ accumulation.

However, in the area of edge helium transport, measurements on DIII-D show a significant dilution of helium as it flows from the plasma core to the pumping plenum, 25 
suggesting that the dynamics of the He flow and recycling in the SOL and divertor may be a limiting factor in the overall removal rate of $\mathrm{He}$ from a reactor system. This dilution will likely be worse in a high-density, radiative divertor as is presentely planned for ITER because of the helium's longer mean free path against ionization as compared to hydrogen. Hence, further studies are needed in this area, with particular emphasis placed on measuring the dilution factor and exhaust capabilities of a gas-target/radiative divertor as is presently planned for ITER. 


\section{REFERENCES}

${ }^{1}$ K. Tomabechi, Plasma Physics and Controlled Nuclear Fusion Research, 1990 (International Atomic Energy Agency, Vienna, 1991), Vol. 3, p. 217.

2 J.L. Luxon, R. Anderson, R. Batty, C.B. Baxi, G. Bramson, N.H. Brooks, B. Brown, B. Burley, K.H. Burrell, R. Callis, G. Campbell, T.N. Carlstrom, A.P. Colleraine, J. Cummings, L. Davis, J.C. DeBoo, S. Ejima, R. Evanko, H. Fukumoto, R. Gallix, J. Gilleland, T. Glad, P. Gohil, A. Gootgeld, R.J. Groebner, S. Hanai, J. Haskovec, E. Heckman, M. Heiberger, F.J. Helton, N. Hosogane, C.-L. Hsieh, G.L. Jackson, G. Jahns, G. Janeschitz, E. Johnson, A.G. Kellman, J.S. Kim, J. Kohli, A. Langhorn, L.L. Lao, P. Lee, S. Lightner, J. Lohr, M.A. Mahdavi, M. Mayberry, B. McHarg, T. McKelvey, R. Miller, C.P. Moeller, D. Moore, A. Nerem, P. Noll, T. Ohkawa, N. Ohyabu, T.H. Osborne, D.O. Overskei, P.I. Petersen, T.W. Petrie, J. Phillips, R. Prater, J. Rawls, E.E.Reis, D. Remsen, P. Riedy, P. Roch, K. Schaubel, D.P. Schissel, J.T. Scoville, R. Seraydarian, M. Shimada, T. Shoji, B. Sleaford, Jr, J.P. Smith, P. Smith, T. Smith, R.T. Snider, R.D. Stambaugh, R. Stav, H. St. John, R.E. Stockdale, E.J. Strait, R. Street, T.S. Taylor, J. Tooker, M. Tupper, S.K. Wong, and S. Yamaguchi, Plasma Physics and Controlled Fusion Research, 1986 (International Atomic Energy Agency, Vienna, 1987), Vol. I, p. 159.

${ }^{3}$ D. Reiter, G.H. Wolf, and H. Kever, Nucl. Fusion 30, 2141 (1990).

${ }^{4}$ D.L. Hillis, K.H. FInken, J.T. Hogan, K.H. Dippel, R.A. Moyer, A. Posieszczyk, D.Rusbüldt, K. Akaishi, R.W. Conn, H. Euringer, D.S. Gray, L.D. Horton, R.A. Hulse, R.C. Isler, C.C. Klepper, P.K. Mioduszewski, A. Miyahara, and G.H. Wolf, Phys. Rev. Lett. 65, 2382 (1990). ${ }^{5}$ D.L. Hillis, J.T. Hogan, L.D. Horton, R.C. Isler, C.C. Klepper, P.K. Mioduszewski, K.H. Finken, K.H. Dippel, A. Pospieszczyk, D. Rusbult, H. Euringer, G.H. Wolf, R.A. Moyer, R.W. Conn, D.S. Gray, K. Akaishi, A. Miyahara, R.I. Budny, and R.A. Hulse, Plasma 
Physics and Nuclear Fusion Research, 1990 (International Atomic Energy Agency, Vienna, 1991), Vol. 3, p. 597.

${ }^{6}$ E.J. Synakowski, B.C. Stratton, P.C. Efthimion, R.J. Fonck, R.A. Hulse, D.W. Johnson, D.K. Mansfield, H. Park, S.D. Scott, and G. Taylor, Phys. Rev. Lett. 65, 2255 (1990).

${ }^{7}$ H. Nakamura, T. Hirayama, Y. Koide, K. Tobita, K. Tani, T. Fukuda, H.Kubo, M. Kuriyama, Y. Kusama, A. Sakasai, T. Sugie, and H. Yoshida, Phys. Rev. Lett. 67, 2658 (1991).

${ }^{8}$ E.J. Synakowski, P.C. Efthinion, G. Rewoldt, B.C. Stratton, W.M. Tang, B. Grek, K.W. Hill, R.A. Hulse, D.W. Johnson, M.W. Kissick, D.K. Mansfield, D. McCune, D.R. Mikkelsen, H.K. Park, A.T. Ramsey, M.H. Redi, S.D. Scott, G. Taylor, J. Timberlake, and M.C. Zarnstorff, Phys. Fluids B 5, 2215 (1993).

${ }^{9}$ H. Saam and the TEXTOR Team, "Siliconization in TEXTOR," J. Nucl. Mater. (in press).

10M.M. Menon, P.M. Anderson, C.B. Baxi, A. Langhorn, J.L. Luxon, M.A. Mahdavi, P.K. Mioduszewski, L.W. Owen, M.J. Schaffer, K.M. Schaubel, and J.P. Smith, Fusion Technol. 22, 356 (1992).

11J.P. Smith, K.M. Schaubel, C.B. Baxi, G.L. Campbell, A.W. Hyatt, G.J. Laughon, M.A. Mahdavi, E.E. Reis, M.J. Schaffer, D.L. Sevier, R.D. Stambaugh, and M.M. Menon, in Proceedings of the 15th Symposium on Fusion Engineering, Hyannis, 1993 (Institute of Electrical and Electronics Engineers, Inc., Piscataway, New Jersey, 1994), Vol. 2, p. 1034. 12K. Schaubel, C.B. Baxi, G.L. Campbell, G.J. Laughon, M.A. Mahdavi, M.M. Menon, C.C. Makariou, J.P. Smith, and M.J. Schaffer, Advances in Cryogenic Engineering 39, (1994). 13 M.R. Wade, D.L. Hillis, J.T. Hogan, M.A. Mahdavi, R. Maingi, W.P. West, N.H. Brooks, K.H. Burrell, R.J. Groebner, G.L. Jackson, C.C. Klepper, G.J. Laughon, M.M. Menon, P.K. Mioduszewski, and DIII-D Team, "Helium Exhaust Studies in ELMing H-mode Discharges in the DIII-D Tokamak using an Argon-frosted Divertor Cryopump," Phys. Rev. Lett. (accepted for publication).

${ }^{14}$ M.H. Redi, S.A. Cohen and E.J. Synakowski, Nucl. Fusion 31, 1689 (1991). 
15K.H. Finken, K.H. Dippel, W.Y. Baek, A. Hardtke, Rev. Sci. Instrum. 63, 1 (1992).

16P. Gohil, K.H. Burrell, R.J. Groebner, J. Kim, W.C. Martin, E.L. McKee, and R.P. Seraydarian, in Proceedings of the 14th Symposium on Fusion Engineering, San Diego, 1992 (Institute of Electrical and Electronics Engineers, Inc., New York, 1992), Vol. 2, p. 1199.

${ }^{17}$ D.F. Finkenthal, PhD. thesis, "The Measurement of Absolute Helium Ion Density Profiles in the DIII-D Tokamak Using Charge Exchange Recombination Spectroscopy," University of California, Berkeley (1994).

${ }^{18}$ T.N. Carlstrom, G.L. Campbell, J.C. DeBoo, R. Evanko, J. Evans, C.M. Greenfield, J. Haskovec, C.L. Hsieh, E. McKee, R.T. Snider, R.E. Stockdale, P.K. Trost and M.P. Thomas, Rev. Sci. Instrum. 63, 4901 (1992).

${ }^{19}$ P.C. Efthimion, M. Bitter, E.D. Fredrickson, R.J. Goldston, G.W. Hammett, K.W. Hill, H. Hsuan, R.A. Hulse, R. Kaita, D.K. Mansfield, D.C. McCune, K.M. McGurie, S.S. Medley, D. Mueller, A.T. Ramsey, S.D. Scott, B.C. Stratton, K.-L. Wong, TFTR Group, H. Biglari, P.H. Diamond, Y. Takase, and V.A. Vershkov, Plasma Physics and Controlled Nuclear Fusion Research, 1988 (IAEA, Vienna 1989), Vol. 1, p. 307.

20L.R. Baylor, W.A. Houlberg, S.L. Milora, G.L. Schmidt, and P, Kupschus, Nucl. Fusion 31, 1249. (1991).

${ }^{21}$ R.A. Hulse, Nucl. Technol. Fusion 3, 259 (1983).

22W. Pfeiffer, F.B. Marcus, C.J. Armentrout, G.L. Jahns, T.W. Petrie, and R.E. Stockdale, Nucl. Fusion 25, 655 (1985).

${ }^{23}$ D.P. Schissel, J.C. DeBoo, K.H. Burrell, J.R. Ferron, R.J. Groebner, H. St. John, R.D. Stambaugh, DIII-D Research Team, B.J.D. Tubbing, K. Thomsen, J.K.G. Cordey, M. Keilhacker, D. Stork, P.E. Stott, A. Tanga, and JET Team, Nucl. Fusion 31, 73 (1991). ${ }^{24}$ B.J. Braams and D.K. Rayevski, Bull. Am. Phys. Soc. 38, 1919 (1993). 
25 M.R. Wade, J.T. Hogan, D.L. Hillis, M.A. Mahdavi, R. Maingi, W.P. West, N.H. Brooks, K.H. Burrell, D.F. Finkenthal, R.J. Groebner, G.L. Jackson, C.C. Klepper, G.L. Laughon, M.M. Menon, P.K. Mioduszewski, and the DIII-D Team, Fusion Technol. 26, 595 (1994). 


\section{ACKNOWLEDGMENT}

We gratefully acknowledge the contributions of the DIII-D operations staff. This research was sponsored by the U.S. Department of Energy, under Contracts DE-AC05-840R21400 with Martin Marietta Energy Systems, Inc., DE-AC03-89ER51114 with General Atomics, W-7405-ENG-48 with Lawrence Livermore National Laboratory, DE-FG03-89ER51121 and DE-FG03-86ER53225 with University of California at Los Angeles, and DE-AC0494DP00789 with Sandia National Laboratories. 